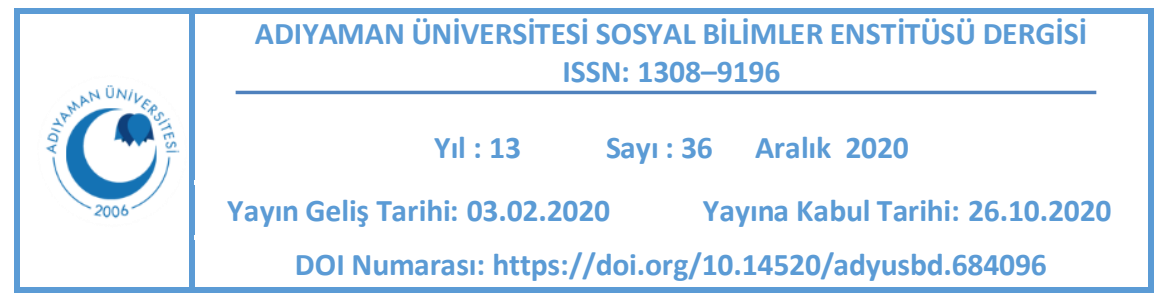

\title{
TERAPIDE PARADOKSAL MÜDAHALELER
}

\author{
ilhan ÇiÇEK* Ahmet TANHAN ${ }^{* *}$
}

\begin{abstract}
$\ddot{O} z$
Terapide müdahale teknikleri gün geçtikçe çeşitlilik arz etmektedir. Herhangi bir terapi kuramında hangi tekniklerin kullanıldığı ve nasıl kullanıldığının iyi bilinmesinin alanda çalışan uzmanların işini kolaylaştırıcı bir rolü olacağı varsayılmaktadır. Bu perspektiften yola çıkılarak, söz konusu bu çalışmada hem bireysel hem de çift terapilerinde kullanılan paradoksal müdahale teknikleri irdelenmiştir. Çalışmanın temel amaçlarından birisi, ruh sağlığı uzmanlarının terapide paradoksal müdahale tekniklerinin arka planı hakkında detaylı bilgi edinmelerini sağlamaktır. Bir diğer önemli amaç ise paradoksal müdahale tekniklerinin nasıl kullanıldığı, hangi istenmeyen davranışlar üzerinde daha etkili olduğunu sistematik bir şekilde ele alarak, ruh sağlığı uzmanlarının bu müdahalelerden faydalanmasını sağlamaktır. Paradoksal müdahale teknikleri, danışanların yaşadıkları problemlere farklı (mizah, abartma, umutsuzca bakma, yaratıcı umutsuzluk gibi) bakış açılarından yaklaşarak problemle ilgili farkındalık kazanarak ben soruna hakimim duygusunu yaşamalarına katkı sağlamaktadır. Postmodern terapilerde daha sık kullanılmaya başlanan paradoksal müdahale tekniklerinin danışanın yaşadığı biyopsikososyal manevi zorlukları ele almada etkili olduğu saptanmıştır.
\end{abstract}

Anahtar Kelimeler: Paradoksal müdahale, postmodern terapiler, psikolojik danışmanlık, ruh sağlığı

Dr. Öğretim Üyesi, Batman Üniversitesi, Sağlık Yüksekokulu, Çocuk Gelişimi Bölümü, cicekilhan7272@gmail.com, Batman, Türkiye.

Dr. Öğretim Üyesi, Adıyaman Üniversitesi, Eğitim Fakültesi, Rehberlik ve Psikolojik Danışmanlık Bölümü, tanhanahmet3@gmail.com, Adıyaman/ Türkiye. 


\title{
PARADOXICAL INTERVENTIONS IN THERAPY
}

\begin{abstract}
Intervention techniques in therapy are diverse day by day. Being familiar and utilizing different interventions enable mental health providers to provide more effective services. Based on this perspective in this study we have examined paradoxical techniques used in both individual and couple therapies are examined. The main purposes of the study are to inform mental health providers (a) about the background of these techniques and (b) how these techniques are utilized effectively with unwanted situations to facilitate a more productive counseling process. These paradoxical intervention techniques are more likely to enable clients or counseltees to look at their issues from a different (e.g., creative hopelessness, exaggeration, humor) perspectives and gain an insight about their issues. In this way the client gains a sense of selfcontrol over the issue and becomes more functional. These techniques are used more in postmodern therapies effectively to address clients' biopsychosocial spiritual issues.
\end{abstract}

Keywords: Paradoxical interventions, postmodern therapies, counseling, mental health.

\section{GiRiş}

Paradoksal müdahaleler yüzyıla aşkın bir süreden beri birçok problemli davranışın tedavisinde etkili bir şekilde kullanılmıştır. Paradoksal müdahalede, terapist, terapötik bir teknik olarak, davranışın ortadan kaldırmasından çok, problemin daha fazla yapılmasını ve kötüleştirilmesini amaçlamaktadır. Burada terapist, danışanın farkındalık kazanarak yaptığı davranışın ne kadar kötü/saçma bir şey olduğunu bilmesini sağlayarak, yaptığı davranışı bırakmasını hedeflemektedir. Paradoksal müdahale tekniği, her ne kadar davranışçı bir teknik olarak sınıflandırılsa da birçok farklı terapide kullanılmaktadır. Bunlardan bazıları kabul ve kararılıık terapisi (Tanhan, 2019: 201-202), diyalektik davranış̧̧ı terapi, stratejik aile terapisi, bilişsel terapi, psikodinamik terapi, logoterapi diğer 
postmodern kısa süreli terapiler (Frankl, 2013:137; Mills, 2000: 5) ve sorun odaklı terapi (Rohrbaugh vd., 1981: 454) olarak karşımıza çıkmaktadır. Bu çalışmada sırasıyla paradoksal müdahale tekniklerin gelişimi, bu tekniklerin geliştirilmesinde katkısı olanlar, temel paradoksal müdahale teknikleri, kullanım alanları ve son olarak sonuç ve tartışma bölümleri şeklinde ele alınmıştır. Alışılagelmişin dışına çıkarak paradoksal yöntemler kullanan teori ya da kuramlar geçmişten günümüze dikkat çekmiş ve terapide yeni bir alternatif oluşturmuşlardır (Rohrbaugh vd.,1981:455; Shoham-Salomon ve Rosenthal, 1987: 25; Tanhan, 2019: 201-202).

\section{Paradoksal Müdahalenin Gelişimi}

Doğrudan öğrenme kuramından türeyen davranışçı tekniklerin aksine, paradoksal müdahaleler bağımsız bir şekilde Knight Dunlap, Alfred Adler, Victor Frankl ve stratejik aile terapisini geliştirenlerin içinde olduğu araştırmacılar tarafından geliştirilmiştir. Paradoksal müdahalenin gelişim süreci Knight Dunlap'tan başlayıp, Alfred Adler, Viktor Frankl, Stratejik aile terapistlerin katkılarıyla olgunlaşmıştır. Son olarak post modern terapiler içerisinde yer alan kabul ve karalılık terapisinin içerisinde, paradoksal müdahale teknikleri kendilerine yer bulmuşlardır. Paradoksal müdahalelerin birçok problemli davranışın tedavisinde etkili olduğu özellikle de geleneksel yaklaşımların etkisiz kaldığı problemlerde olumlu sonuçların elde edildiği görülmektedir (Mills, 2000: 6). Paradoksal müdahale tekniklerin gelişimine ilişkin detaylı bilgiler bulgular kısmında yer verilmiştir.

\section{YÖNTEM}

$\mathrm{Bu}$ çalışma bir derleme çalışması olup paradoksal müdahaleleri konu alan makale, tez veya kitap gibi basılı kaynaklardan faydalanılmıştır. Paradoksal müdahaleleri ele alan çalışmaların azlığı nedeniyle sistematik bir literatür 
taraması yerine Türkiye'deki bir üniversitenin veri tabanı ve Google Scholar kullanılmıştır. Arama motoruna anahtar kelime olarak "paradoksal müdahaleler" ve "terapide paradoksal müdahale" ayrı ayrı Türkçe ve Ingilizce yazılarak bunlardan birisini ya da ikisini içeren kaynaklar gözden geçirilmiştir. Bulunan kaynak sayısı fazla olmadığından sistematik bir süreç ya da sayı süreci izlenmemiştir.

\section{BULGULAR}

$\mathrm{Bu}$ bölümde öncelikle araştırma sonucunda elde edilen paradoksal müdahalelerin gelişiminde katkısı olan başlıca kişi ve terapi kuramlarına yer verilmiştir. Daha sonra paradoksal müdahale tekniklerinin uygulama alanlarının ne olduğuna değinilmiştir. Son olarak paradoksal müdahale tekniklerinin nasıl kullanıldığına ilişkin bulgular sunulmuştur.

Knight Dunlap: 1920'li yıllarda danışanlara uyguladığı "negatif uygulama" prosedürü ile tırnak yeme, altını ıslatma, tik ve kekemelik gibi birçok davranış problemin tedavisinde başarılı sonuçlar elde etmiştir. Dunlap’a göre istemli bir şekilde yapılan bir davranışın, istenmeyen davranışın oluşumunu engeller ve zamanla istenmeyen davranışı ortadan kaldırır. Dunlap, bu durumu paradoksal niyet tekniği biçiminde ele almıştır (Riebel, 1981: 22).

Alfred Adler: Adler, paradoksal müdahale tekniğini semptomunu reçeteleme olarak tanımlamıştır (Sharf, 2014: 128). Adler'in psikoterapideki amacı danışanın davranışının değişiminden öte, problem olarak getirilen davranışın devam etmesini ve danışanın davranış üzerinde daha geniş bir hakimiyet alanın oluşmasına olanak sağlamasına dönük müdahalelerde bulunur. Uygulama esnasında, danışanların semptomlarını daha da geliştirmeleri için danışman tarafından cesaretlendirilirler. Ayrıca Adler, davranış problemlerin tedavisinde 
paradoksal müdahale ile birlikte mizah unsurunu da etkili bir şekilde kullanmıştır (Mills, 2000: 8; Sharf, 2014: 128).

Viktor Frankl: Paradoksal müdahale tekniklerini kullananlardan biri de Viktor Frankl'dır. Logoterapinin kurucusu olan Viktor Frankl, logoterapinin asıl amacının bireyin kendi yaşamında anlam bulmasını sağlamak olarak nitelendirmiştir. Aynı zamanda hayatın anlamını bulmak ya da inşa etmek insanın en önemli motivasyonudur. Post-modern bir terapi olarak da bilinen logoterapide paradoksal müdahaleler sıkça kullanılmaktadır (Murdock, 2013: 180). Frankl, Adler'den sonra paradoksal müdahaleleri ayrı bir terapötik teknik olarak kullanan ve sistematik hale getiren kişi olarak bilinmektedir. Felsefi bir bağlam olarak, logoterapinin bir parçası olan paradoksal niyeti geliştirmiştir. Paradoksal niyet tekniği, kişinin kaygı yaratan ortamları ve durumları hayalinde tekrar tekrar canlandırması ve bu sırada kaygıyı olabildiğince yoğun yaşaması şeklinde formüle edilen davranışçı bir terapi tekniğidir. Paradoksal niyet tekniğine, taşırma terapisi veya çöktürme terapisi (implosive therapy) de denir (Mills, 2000: 9; Altıntaş ve Gültekin, 2005: 124). Paradoksal müdahale tekniklerinin en belirgin şekilde kullanıldığı terapinin logoterapi olduğu söylenebilir (Weeks, 2013: 73).

Stratejik Aile Terapisi: Stratejik aile terapisi kurucuları arasında sayılan ve Milan grubunun içinden çıkan Milton Erickson'ın paradoksal tekniklerin kullanılmasında önemli katkıları olmuştur (Mills, 2000: 34). Stratejik aile terapistlerinin, aile terapisinde odak noktası paradoks kuramı ve paradoksal tekniklerdir. Stratejik aile terapistleri, direncin ailenin bir semptom altında, dengesini sürdürme çabası içerisinde olduğu durumlarda ortaya çıktığını belirtmektedirler. Sonuç olarak, semptomun ortadan kaldırılması (yani terapinin amacı) ailenin denge sistemine zarar vereceği için reddedilecektir. Bu yüzden terapistler, aile üyelerinden işbirliği yerine reddedici davranışlar beklemelidirler. 
Burada danışanların potansiyel direnç mekanizmalarından yararlanılır. Aile üyelerine terapist tarafından paradoksal yani çelişkili yönergeler verildiği zaman, aile üyeleri, terapistin önerisini ya kabul ederek problemin üzerinde hakimiyet kurarlar ya da reddederek problemin üstesinden gelerek değişirler (Dallos ve Draper, 2012: 54; Worden, 2013: 182).

Kabul ve Kararlılık Terapisi: Davranışçı terapilerde üçüncü dalga altında yer alan kabul ve karalılık terapisi seçkisiz atama ve kontrollü deneysel çalışmalar sonucu itibariyle en etkili terapilerden birisidir (Tanhan, 2019: 200). Terapi insan doğasının iyilik (normal, pozitif) halini açıklamak için psikolojik esneklik modelini kullanmakta ve model altı temel süreçten oluşmaktadır (an'a esnek bir şekilde odaklanma, değerler, kararlı davranış, bağlam içinde benlik, ayrışma, kabul) (Tanhan, 2019: 202). Diğer taraftan terapi insanın psikopatolojik durumunu açıklamak için de psikolojik esneksizlik modeli üstüne kurulu olup bu model de altı temel kavramın üstüne inşa edilmiştir (ana esnek bir şekilde odaklanamama, değerlerin yokluğu ve zayıf ya da çarpıtılmış olması, dürtüsellik ya da eylemsizlik, içerik olarak kavramsallaştırılmış benlik, bilişsel birleşme ya da kaynaşma, (yaşantısal kaçınma). Tanhan (2019: 201-202) bu iki modelin bir düzlemin iki uç noktasını temsil ettiği üzerinde düşünülebileceğini ifade etmiştir. Terapi genel olarak insanın psikolojik esneksizlik modelinin bir veya birkaç sürecini (örn., ana esnek odaklanmama, yaşantısal kaçınma) yaşayan danışanı terapinin sürecine uygun bir şekilde psikolojik esneklik modelinin gereken sürecine (örn., ana esnek şekilde odaklanma, kabul) doğru yol aldırmaya çalışır. Bu süreçte terapist bazen paradoksal müdahaleler kullanır ama özellikle danışan normal psikolojik danışma sürecinde ilerlemiyorsa ve tıkanmış ya da işlevsel olmayan durum devam ediyorsa o zaman terapist kabul ve kararlılık terapisi bağlamında paradoksal müdahaleler kullanmaktadır (örn., yaratıcı umutsuzluk, kaynaşmış ya da birleşmiş düşünce). Örneğin bir danışan üniversitede okuduğu bölümden umutsuz olduğunu, bölümün hiçbir avantajının olmadığını, terapistin tüm 
çabalarına rağmen bölümün hiçbir avantajını dile getirmediğinde terapist danışanla oluşturduğu terapötik ilişkiyi de göz önüne alarak paradoksal bir şekilde danışana bu bölüme gitmesinin dünyanın en büyük hatası olduğunu ve bu bölümün kesinlikle okunmaması gerektiği şeklinde geri bildirim vermeye çalışabilir. Terapist danışanla terapötik (empatik, koşulsuz kabul, tutarlı) ve güvenli bir ilişkisi kurmuşsa danışan terapistin bu paradoksal yaklaşımını büyük bir ihtimalle kavrayacak ve olaya farklı bir perspektiften daha işlevsel ve esnek bakma ihtimali artacaktır. Kabul ve kararlılık terapisinde bu gibi paradoksal müdahaleler ele alınan altı sürece göre daha çok bilişsel, duygusal, davranışsal ya da bunların karışımı olabilir.

\subsection{Terapi Uygulamalarında Paradoksal Müdahaleler}

Terapi uygulamalarında paradoksal müdahaleler iki şekilde karşımıza çıkmaktadır: Paradoksal niyet ve paradoksal müdahale.

\subsubsection{Paradoksal niyet}

Paradoksal niyet tekniği ilk defa Adler tarafından semptomu reçeteleme ismiyle terapide kullanılmasına rağmen, Viktor Frankl tarafından geliştirilip sistemleştirilmiştir (Altıntaş \& Gültekin, 2005: 124; Sharf, 2014: 128). Paradoksal niyet tekniği psikolojik danışmanlık uygulamalarında kullanılmaktadır. Paradoksal niyet tekniği, korkunun, korkulan durumu yarattığı ve aşırı isteğin, arzulanan şeyi imkânsız kıldığı gerçeğine dayanmaktadır (Frankl, 2013: 138; Sharf, 2014: 128). Frankl (2013: 138-139) paradoksal niyetin nasıl çalıştığını beklenti kaygısı denen mekanizmayla açıklar. Bu mekanizma şu şekilde uygulanmaktadır; önce belli bir semptom, danışanda tekrar ortaya çıkabileceği konusunda korkulu bir beklenti yaratır. Korku, her zaman için tam da korkulan şeyi yaratma eğilimi gösterir. Bu nedenle beklenti kaygısı, danışanda meydana gelmesinde korktuğu şeyi tetikleme eğilimi gösterir. Burada bireyin korktuğu 
durumdan kaçınması yerine, bu durumun üstüne daha fazla giderek hatta abartılı bir biçimde yüzleşmesini sağlayarak, oluşmuş olan kısır döngüyü ortadan kaldırmaya çalışmaktadır. Paradoksal niyet tekniğinin amacı, danışanın korkudan kaçma niyetini tamamen tersine çevirerek kaçınmayı ortadan kaldırmak ya da etkisini zayıflatmaktır (Carlson vd., 2006: 112; Frankl, 2013: 138-139).

Adler'e göre, paradoksal niyet tekniği terapide güçlü bir değişiklik yaratır. Bu teknikte, danışanın rahatsız olduğu konuyu düşünmesi ve gerekiyorsa korktuğu davranışı yapması istenir. Aynı zamanda danışanın duyguları ile temas kurması ve korktuğu durum karşısında duyarsızlaşması sağlanır (Prinz ve Arkin, 1994: 352). Adler, terapide danışanlarından kendilerini rahatsı eden belirtileri daha yoğun olarak yaşamalarını ister. Paradoksal niyet tekniğinin ardındaki temel düşünce, danışanın semptomlarının farkına varmasını sağlamak ve semptomlar üzerinde bir hâkimiyet kurmasını mümkün kılmaya çalışmaktır. Ayrıca danışanın yaşadığı paradoks ona saçma gelmeye başladığı zaman, danışan semptomlarından vazgeçmeye başlar (Carlson vd., 2006: 112). Altıntaş ve Gültekin (2005: 125) paradoksal niyet tekniğinde kişi fobi belirtileri sergiliyor ise korktuğu şeyin olmasını arzulamaya yönlendirilmesi gerektiğini ifade etmişlerdir. Böylece kişinin korkularından kaçmasına ya da korkularıyla mücadele etmesine son verilmiş olur. Böylelikle sıkıntı yaratan korkunun yerini paradoksal bir niyet alır, sonuç olarak da beklentisel kaygı durumunun kısır döngüsü kırılmış olur. Örneğin, evde yalnız başına kaldığında bayılmaktan korkan bir kişiden, evde yalnız kalarak bayılmak için çaba göstermesi istenebilir. Kişi bunu yapamadığını anlar ve bu fobi durumuyla başa çıkabilecek düzeye gelebilir. Cooper (2016: 67) paradoksal niyette, danışana sıkıntı veren bir semptom veya yaşantıyı bilerek sonuna kadar yaşaması için onu cesaretlendirme yani semptomu arttırma olduğunu açıklamıştır. Bu durum 
kişinin korkulan şey ile yüzleşmesi sonucunda yaşadığı korkuyu yenmesinde etkili olmaktadır.

Paradoksal niyet tekniğinde her şey bilişsel ve duyuşsal düzeyde olup bittiği için, fiziki bir tehlike söz konusu değildir ve kaygı tepkisi pekiştirilmediği için korku yavaş yavaş azalır. Bu teknikte genelde birey korktuğu durumdan ne kadar kaçınırsa o kadar korkunun etkisinde kalacaktır ve olumsuz etkileri de o derece artacaktır. Öte yandan kişi kaçınmak istediği şeyi ne kadar arzularsa, o oranda o durumdan uzaklaşma ihtimali artmaktadır. Daha açık bir ifadeyle örneğin, sunum yapmaktan korkan bir öğrenciye "elin ayağın birbirine dolasın", "daha önce titremediğin kadar titre" şeklinde yönergelerin verilmesi öğrencinin daha fazla rahatlamasını ve sunum yaparken titrememesini sağlayabilir ya da sonucunu düşündüğü kadar olumsuz olmadığını deneyimler. Adler, danışanın davranışını olduğu gibi kabul ederek, danışanın sergilediği istenmeyen duygu, düşünce ve hislere yer açma ile danışanı rahatsız eden şeyin daha az çekici geleceğine inancı taşıyacağını ve davranış üzerinde kontrolünün daha kolay olacağını dile getirmektedir. Burada, danışanın kendi durumuna gülebilmesini gösterecek yeni bir bakış açısı geliştirebileceği sağlam bir mizah duygusundan yararlanılması tekniğin daha etkili bir şekilde uygulanmasına katkı sağlayamaktadır (Frankl, 2013: 140 Sharf, 2014: 128-129; Seligman, 2001:83).

Paradoksal niyette mizah unsuru önemli bir rol oynamaktadır (Carlson vd., 2006: 110; Cooper, 2016: 68). Mizah duygusunu bilinçli olarak uygulamak, Frankl'in paradoksal niyet yönteminin ayrılmaz bir parçasıdır. Örneğin, terlemekten korkan bir danışan, izleyenlere terlemenin gerçekten neye benzediğini gösterdiğini, çevredeki her şeyi ıslatacak kadar ter döktüğünü düşünmesi ve bu durumda eğlenmesi istenebilir. Logoterapide mizah, kendini aşma olarak adlandırılan insana özgü yetinin bir dışavurumu olarak değerlendirilmesi olarak tanımlanır. Kendini aşan birey, aynı zamanda yaşadığı problemin de üstesinden 
gelebilir şeklinde yorumlanabilir. Bireyin korktuğu şey her ne olursa olsun, korkusunu sonuna kadar yaşaması, son derece büyük olan bu korku ile kişinin bir birey olarak kendine olan gülme kapasitesi ile bağlantı kurması ve böylece kendi yaşamının bir parçası olan rahatsız olduğu semptomlarından uzaklaşması sağlanır (Frankl, 2013:132; Murdock, 2013: 192). Frankl (2009: 56), birey, kendinden uzaklaşma yani deneyimlediği şeylerin ötesinde kendini görmesi yetisi sayesinde kendisiyle eğlenme, kendine gülme, kendi korkularıyla dalga geçme kabiliyetine sahip olduğunu ifade etmiştir. İnsan, kendini aşma kapasitesi sayesinde, kendini unutabilmekte ve varoluşuna bir anlam verme arayışına girebilmektedir (Frankl, 2013: 133). Birey obsesyonları veya anksiyetesi ile baş edebilmek için mizah unsurlarını içeren abartılı bir imajinasyon (hayal etme) ile deneyimlediği rahatsız edici belirtilere veya konuyla kendisi arasında bir mesafe oluşturur. Bireyin geliştirdiği korkuların tam da korkulan şeyin gerçekleşmesine yol açtığı düşünülür. Kaçınma yolu ile kaygıyı azaltma mekanizması bireye uzun vadede yarar sağlamayacağından birey, davranışının korkulan sonuçlarını bilinçli olarak arzulamaya yönlendirilir. Kendi korkuları ile eğlenebilen, içinde bulunduğu durumu mizahi bir dille eleştirebilen birey, zamanla korkularından uzaklaşabilecektir. Bu yöntemle kişinin içine girdiği kısır döngüyü kırması ve semptomlarının zayıflanması sağlanır (Altıntaş ve Gültekin, 2005: 126). Birey semptomlarıyla mücadele etmekten vazgeçtiği ve bunun yerine semptomlarını mizahi bir şekilde ele aldığı, espri konusu yaptığı zaman, yaşadığı kısır döngü derece derece kişi üzerindeki etkisi zayıflamakta ve zamanla son bulabilmektedir. Sonuç olarak birey korkularını görmemeye başlar. Paradoksal niyet tekniğinin kullanılmasından amaçlanan, danışandaki semptomların azalması, danışanın işlevselliğinin artışı, espri yeteneğinin artışı ve bakış açısının değişmesidir. Victor Frankl, paradoksal niyette metaforları da kullanır. Başlıca kullanılan metaforlar, iki gözle görme, derinliği olmama ve birbiriyle çelişkili 
resimler bunlara örnek olarak gösterilebilir (Budak, 2005: 25; Carlson vd., 2006: 111; DiTomasso ve Greenberg, 1989:2268; Sparrer, 2012: 90).

Davranışçlık yönelimli araştırmalar, logoterapinin paradoksal niyet tekniğinin uygulamasının işe yararlılık konusunda destekleyici sonuçların elde edildiği sonucuna varılmıştır. Davranış̧̧ı yönelimli yaklaşımlar için geçerli olan, psikodinamik yönelimli yaklaşımlar için de geçerlidir. Bazı psikanalistler, paradoksal niyeti kullanmanın yanı sıra, bu yolla sağlanan başarıyı Freudçu terimlerle açıklamaya çalışmaktadır (Mills, 2000: 38; Riebel, 1981: 32). Psikanalitik bir modelde paradoksal niyet -fobik veya saplantıll-zorlanmalı semptomun kendisinden daha az ruhsal enerji harcaması gerektiren savunmaları kullanmak yoluyla semptomların hafifletilmesi olarak ele alınmaktadır. Paradoksal niyetin her başarılı uygulanışında, ilkel benliğin dürtüleri doyurulur (insanın içinden geldiği gibi davranması istenir), süper egonun bir ittifakı olur (kişi ben ne yapıyorum duygusunu yönetir), egonun kendisi de güç kazanır (kişinin bilinçlilik yönü güçlü olur) ve daha az kısıtlanır. Bu durumun doğal bir sonucu olarak, kaygının yavaşlaması ve semptom oluşumunun azalması sağlanmış olur (Frankl, 2013: 140). Terapide kullanılan bir diğer paradoksal teknik, paradoksal müdahaledir (Brown ve Christensen, 1999: 66).

\subsubsection{Paradoksal müdahale}

Paradoksal müdahale, aile terapisine özgü bir kavramdır. Genel olarak, ailenin terapistin sunduğu yönergelere uymada problem yaşadığında kullanılmaktadır. Terapist aile üyelerine problemli davranışı yapmaları için açık bir şekilde onları teşvik eder. Bir yönüyle aile üyelerinin kendi dengelerini korumalarını sağlamaya dönük bir tekniktir. Paradoksal müdahale, stratejik aile danışmasında en tartışmalı ve güçlü tekniklerden biridir (Gladding, 2012: 376; Özburun, 2018: 181). Pozitif çağrışım yoluyla aslında ailede problem yaratan problemli davranış, 
danışman tarafından ailenin dengesini sürdürmeye yönelik olumlu bir davranış olarak yeniden şekillendirilir. Bu davranışı yeniden tanımlama süreci, ailede paradoksun oluşmasına neden olur. Çünkü aile üyelerinin problem olarak nitelendirdiği davranış aslında ailenin dengesini korumaya yönelik bir çaba olarak danışman tarafından yeniden adlandırılır. Danışman paradoksal bir müdahale ile aile bireylerinin problem olarak gördüğünü değiştirmemelerini talep eder. Bu da ailenin bu problem üzerinde düşünmesine ve değişim için harekete geçmesine imkân sağlayabilir. Aile soruna alternatif bir çözüm yolu buluncaya kadar danışmanın oluşturduğu çifte çıkmazı devam ettirilir (Kesici vd., 2013: 130-131). Aile terapisinde uygulanan paradokslar, ilk başta terapinin hedefleriyle çelişir gibi görünen, ama aslında amaçları gerçekleştirmek için organize edilen taktikler ve manevralardır. Paradokslar bu bağlamda semptomları saptamak, semptomlara pozitif değerler biçmek, semptomlara pozitif anlamlar vermek, semptomları desteklemek, belirli semptomların hızlı bir şekilde kaybolacağı korkuları ifade etmek için uygulanan stratejileridir (Palazzoli, Cirillo ve Sorrentino 1989: 187). Söz konusu terapi sırasında aile hem istikrar için hem de değişim için paradoksal bir talepte bulunur (Becvar ve Becvar, 1998: 56). Stratejik aile terapisinde paradoksal müdahaleler, aile üyelerinin verilen yönergelere uymakta zorluk çektiklerinde kullanılır. Burada danışma sürecindeki amaç, aile üyelerinin yaşadıkları durumun bir problem olduğu ve bu problemi fark etmeleri son olarak ailenin yaşadığı problem üzerinde hâkimiyet kurmalarını sağlamaktır (Ünal, 2013: 34).

Stratejik aile terapisinde paradokslar iki şekilde uygulanmaktadır. Bunlar: Tavsiye verici (prescriptive) ve betimsel (desriptive) paradokslardır. Tavsiye verici paradokslarda danışana bir şey yapması söylenir. Tavsiye verici paradokslar olumlu bir anlam vererek bir şeyleri yeniden nitelendirir. Örneğin işlerini zamanında tamamlayamayan, işini ağırdan alan ve bu nedenle yardım arayan bir danışana bir sonraki oturuma kadar işlerini tamamlaması istenmez. 
Tam tersine danışana boşa harcadığı zamanları ve bunların ne kadar sürdüğünü kaydetmesi istenir. Bu nahoş görev genellikle danışanların işini ağırdan alma davranışlarını azaltır. Ya da danışan ilerleyen oturumlarda, kaydedecek bir şey bulunmadığın, çünkü bütün işlerini zamanında yaptığını bildirebilir. Her iki durumda da danışan, davranışları hakkında daha çok farkındalık kazanır veya kendisinin şikâyetçi olduğu kadar işini ağırdan alan bir kişi olmadığını öğrenebilir. Betimsel (desriptive) paradoksta ise semptomun yeniden tanımlanması, ifade edilmesi süreci vardır (Nazlı, 2014: 87). Danışanın yaptığı istenmeyen davranışın, danışanı rahatsız etmeyecek şekilde tekrar tanımlanmasıdır.

Stratejik aile terapisinde terapist, ailenin doğrudan müdahaleye direnç gösterebileceğini kanaat getirdiğinde paradoksal yönergeler verir. İki genel paradoksal tür vardır: Kısıtlayıcı emir (danışana değişmemesinin söylenmesi) ve semptom reçetesi. Bu müdahaleler, danışanı kazananın olmadığı bir duruma sokmak için kullanılır. Örneğin, kusma konusunda obsesyonu olan bir çocuğa, günde bir saat evin mutfağında oturması ve orada sadece kusmayı düşünmesi söylenir. Eğer çocuk bu yönergeye uyarsa, o zaman bu semptomu üzerinde kontrol sahibi olabilir. Eğer uymazsa da, semptom ortadan kalkmış ya da etkisi zayıflamış olur (Haley ve Richepory-Haley, 2003: 128). Paradoksal yönergelerin özel bir şekli, eza çekmektir. Eza çekmenin amacı, yaşanan semptomun yarattığı sıkıntıyı olağan olarak olduğundan daha fazlasıyla yaşamaktır, özellikle de başkalarıyla olan ilişkileri kontrol etmek bakımından önemlidir. Sonuç olarak, danışan kendi isteğiyle semptomundan vazgeçecektir. Bu yaklaşımın arkasındaki varsayım, semptomunu bırakan bireyin daha sonra başkalarıyla ilişki kurmak için daha uyumlu olan yeni yollar bulacak olması düşüncesidir (Brown ve Christensen, 1999: 67; Murdock, 2013: 440). 
Paradoksal müdahaleler bir bireyin ya da ailenin fonksiyonelsiz davranışlarını bırakması için oldukça elverişli bir yoldur. Stratejik aile danışmanı, semptom ortaya çıktığında (örneğin sürekli ellerin terlemesi) danışana zor ve zevksiz bir iş yapması için direktif verir (örneğini gecenin bir yarısı mutfak tabanlarını cilalamak gibi). Böylece semptomun yapacağı sıkıntıdan daha büyük bir sıkıntı yaşanması sağlanır. Danışanın semptomlarına uygun zor bir görev seçilerek uygulatılır (Nazlı, 2014: 89).

\subsubsection{Paradoksal müdahalenin uygulanması}

Paradoksal müdahale tekniğinde terapist, ailelere ve aile üyelerine zaten yapmakta oldukları şeyi yapma izni verir ve böylelikle direnci azaltma veya elimine etme amacı taşır. Paradoksal müdahale tekniğinde, yönerge verme gibi daha basit tekniklerin kullanılabileceği durumlarda özellikle de psikolojik danışmanlık eğitimini hala alan ya da yeni bitiren danışmanlar tarafından paradoksun kullanılmaması gerekliliği akıldan çıkarılmamalıdır (Gladding, 2012: 377). Paradoksun deneyimsiz psikolojik danışmanlar tarafından kullanılması, süpervizyon eşliğinde ve iyi planlanmış bir şekilde olmalıdır. Paradoksal müdahaleler, danışma sürecinde danışan birbiriyle tutarsız iki yönerge şeklinde verilir. Verilen yönergede, yönergeye uyulmamasına dair yönerge verilirse bu paradoksal bir iletişim olur. Örneğin "içinden geldiği gibi davranmanı istiyorum". Kişi hem bu yönergeye uyup, hem de içinden geldiği gibi davranamaz. Sonuç olarak, danışanın problem üzerindeki etki alanının perçinlenmesi sağlanmış olur. Danışman, aile üyelerinden işbirliği yerine, reddedici davranışlar beklemektedir. Aile üyelerine danışman tarafından çelişkili yönergeler verildiği zaman, aile üyeleri danışman önerisini, ya kabul ederek ya da reddederek değişirler (Worden, 2013: 182-183). Danışma sürecinde aile üyelerine, yakındıkları problem davranışı sürdürmeleri ve abartmaları istenir. Burada danışman, ailelerin özelliklerine göre önerilerinde değişikliğe gidebilir (Nichols, 2013: 223). 
Bireysel ve aile terapilerinde paradoksal müdahale tekniklerinin uygulanması değişik şekillerde olmaktadır. Aile ve bireysel terapileri incelendiğinde paradoksal müdahale basamakları; yeniden tanımlamak, yönerge vermek ve sınırlandırma biçiminde olduğu görülmektedir (Worden, 2013: 183).

Yeniden tanımlama (Redefining): Terapistin semptomu yeniden tanımlaması, danışanın davranışı daha sık bir şekilde yapmasını ve devam etmesini sağlar. Yeniden tanımlama aşaması yeniden yapılandırma kavramına benzer. Örneğin uyku problemi yaşayan birine normal zamanda yatağına girmesi, ancak olabildiğince yatakta uyanık kalması gerektiğinin söylenmesi şeklinde izah edilebilir (Worden, 2013: 183-183). Buradaki amaç, kavramsal/duygusal durumları ya da yaşanmış olaylarla ilgili danışanın bakış açısını değiştirmek ve bunun yerine benzer gerçekler yerleştirmektir (Watzlawick vd., 1994: 96). Danışanın istemediği bir şekilde davranışının yeniden tanımlanması veya yeni bir çerçeveye yerleştirilmesi, danışan için hoş olmayan bir yaşantıdır. Örneğin danışma sürecinde, danışanın kızgınlık problemi, danışman tarafından birisine karşı özen göstermenin bir yolu olarak yeniden tanımlanabilir. Bu durum danışanın zihninde problem ile ilgili yeni pencereler açmasına fırsat sağlayabilir. Bir diğer tanımla, eğer danışan belli bir işi yapmaktan kaçınıyorsa, psikolojik danışman bu davranışı danışanın kendisini veya başkalarını koruması şeklinde tanımlayabilir. Bu gibi bir yeniden tanımlama, danışanın davranışının kontrolünü ele geçirmesine imkan sağlar (Murdock, 2013: 441). Yeniden tanımlamada değişmeyen gerçeğe ilişkin, danışanın gerçeğe yönelik bakış açısının farklılaşmasına olanak tanınır (Özabacı ve Erkan, 2013: 62). Ruh sağlığı uzmanı, danışanla işbirliği içinde etkili bir yeniden tanımlanma ile rahatsı edici duygu, düşünce veya davranışı iyi tasarlanmış bir biçimde yeniden adlandırarak söz konusu davranışı kişisel veya sosyal bakımından danışan tarafından daha kabul edilebilir kılar (Hackney ve Cormier, 2008: 195). Murdock (2013: 441), problemi yeni bir çerçeveye yerleştirmenin, danışan için anlaşılmaz ve çözülemez bir 
sorunun çözülebilir olduğu hususunda düşünmesini sağlayıcı bir rolü olduğunu ifade etmektedir. Yeniden tanımlama sürecinde, öfke sevgi olarak, acı çekme özveri ve uzaklaşma ise yakınlığı güçlendirmenin bir yolu olarak tekrar tanımlanabilir (Goldenberg ve Goldenberg, 2008: 227).

Yönerge vermek (Prescribing): Terapist aile üyelerine yönerge vererek aynı davranışı daha sık göstermelerini isteme amacı taşımaktadır. Terapiste göre, eğer aileler istedikleri zaman tartışmalarını, problemlerini başlatırlarsa bunlar üstünde zamanla başlangıçta olduğundan daha fazla kontrol sahibi olacaklardır (Worden, 2013: 184). Paradoksal ezalar, semptomun yaşanması gerektiren yönergelerdir. Başka bir açıdan, sadece semptomu yaşamak da bir eza olarak düşünülebilir. Aile üyelerinin şikâyet ettikleri problemden daha yoğun ve sıkıntılı bir yönergenin verilmesi amaçlanır. Danışandan sorunlu davranışı özellikle ve hatta abartarak yinelemesi istenir, örneğin kaygılı bir bireyden sorunlu durumlardaki gibi bilerek olabildiğince gergin davranması beklenir. Gerçekte danışan yönergeyi takip ederse, gittikçe daha gerginleşir; sonuç olarak danışanın yönergeye uyması, gerginliğin danışanın kontrolü altında olduğunu fark etmesini sağlar ve gerginliğin kontrol edilebilir olduğunu öğrenmiş olur. Belli bir süre sonra problem olan davranışın, danışanın dünyasından yok olmasına imkan sağlayabilir (Dowd ve Milne, 1986: 263; Hackney ve Cormier, 2008: 197; Murdock, 2013: 442). Örneğin sınırlı bir fiziksel semptomdan-baş ağrısı, uykusuzluk, sinirlilik hali-şikâyet eden bir danışana, gelecek hafta boyunca, genellikle belirli zamanlarda, o semptomu artırmak için elinden geleni yapması gerektiği söylenebilir. Danışanın bu direktif doğrultusunda hareket etmesi, genelde semptomun azalmasıyla sonuçlanır ki bu istenilen bir durumdur. Ancak danışan semptomu arttırsa bile, bu durum danışan için daha da iyidir. Zira danışan, danışmanın talimatına uymuştur ve problemin değişebileceğini göstermiştir (Weakland vd., 1974: 95). Sonuç olarak, danışanın değişim tünelinin içine girdiği ve değişmek için güçlü bir irade gösterdiği şeklinde yorumlanabilir. 
Sınırlamak (Restraining): Aile değişim işaretleri gösterdiğinde terapistin davranışı nasıl ve ne kadar yapması gerektiği konusunda aileye belirtmesi ve o davranışı çerçevelemesidir. Sınırlamada aktif bir şekilde terapistin danışanların cesaretlerini kırması ya da değişimi yasaklamasıdır. Terapist aile üyelerine çok hızlı gidiyorsunuz, yavaşlayın şeklinde direktifler vererek, onları sınırlandırmaya çalışır. Aile üyelerinin sınırlandırılması, probleme ilişkin farkındalık edinmelerini ve yaşadıkları durumu daha açık bir şekilde görmelerini beraberinde getirir (Murdock, 2013: 442). Danışman, aile üyelerinde değişme belirtileri gördüğünde onları sınırlandırır ve hızlı gitmemeleri gerektiği şeklinde uyarılarda bulunur (Nazlı, 2014: 92). Eğer müdahalelerin zamanlaması iyi ayarlanırsa ve aile üyeleri yeniden yapılandırmayı kabul ederlerse, davranışlar değişir ve problemin üzerinde hâkimiyet kurarlar (Worden, 2013: 184).

\section{TARTIŞMA ve SONUÇ}

Paradoksal teknikler, sabit, katı ve tekrar eden davranış yapıları gösteren birey ve ailelerle kullanmak etkili olabilmektedir. Terapist ile arasında güçlü bir ilişki ve güvene dayalı bir iletişim olduğunda bu tekniklerin kullanılması uygundur. Terapist ile aile arasında bu uyum gerçekleşmediğinde, aile paradoksal müdahale tekniklerini garip karşılayabilir ve terapide istenilen randıman sağlanmamış olur (Worden, 2013: 176-178). Öte yandan kontrole ihtiyaç duyan, kargaşa ortamın olduğu düzensiz ailelerde, paradoksal müdahaleler pek fayda sağlamazlar (Ascher vd., 1986: 125). Bu açıklamalar ışığında paradoksal tekniklerin kullanımında öncelikle danışman ile aile arasında güven ilişkisinin tam sağlanmış olması ve ailenin özelliklerinin bu tekniklerin kullanılmasına uygun olup olmadığı tespit edilmesi gerekliliği zorunluluk arz etmektedir. Zira bu tekniklerle ilgili araştırmacıların ulaşabildikleri araştırmaların çok sınırlı olduğu ve araştırmaların çoğunun güncel olmadığı görülmüştür. 
Paradoksal niyet tekniği, uyku bozukluğu, fobi içeren rahatsızlıklar, anksiyete ve depresyon üzerinde güçlü bir etkiye sahip olduğu vurgulanmaktadır. Ayrıca bu teknik, bireysel, çift ve grupla psikolojik danışmada kullanılmaktadır (Baltacı, 2016: 7; Frankl, 2013: 141). Herhangi bir travmatik olay yaşamış ya da patolojik bir rahatsızlığı olan bireylerde, paradoksal niyet tekniğini uygulamak ve diğer terapötik tekniklerle birleştirerek çalışmalar yürütmek, paradoksal tekniklerin daha sistematik bir şekilde uygulanmasını sağlar ve daha verimli olur (Ascher vd., 1986: 126; Nietzel vd., 2003: 46). Öte yandan paradoksal niyet tekniği bütün problemlerde kullanılmadığından danışman için sınırlayıcı bir nitelik taşımaktadır (Ascher ve Schotte, 1999: 72). Bu yüzden sadece paradoksal müdahale tekniklerini bilmek, etkili bir psikolojik danışmanlık için yeterli değildir. Zira bu sınırlılıktan dolayı danışanın getireceği farklı problem alanlarında, danışman güçlü bir şekilde cevap veremeyebilir.

Sonuç olarak paradoksal tekniklerin kullanıldığı aile, çift ve bireysel terapilerde etkili çıktılar elde edildiği anlaşılmaktadır. Terapist ve danışan arasında güçlü bir ilişki ve uyum olmadan paradoksal teknikler uygulanmamalıdır. Bu uyum olmadan paradoksal teknikler uygulanırsa, aile bu paradoksal müdahaleleri tuhaf bakışlarla karşılayabilir. Erken uygulanmış bir paradoksal teknik ailenin bir sonraki oturuma gelmemesine neden olabilir. Bu bağlamda paradoksal müdahaleleri kullanmak için terapistin deneyimli olması önemlidir. Paradoksal müdahaleler, birçok davranış problemin tedavisinde etkili ve olumlu sonuçlar elde etmesi yönüyle öne çıkmaktadır. Sınav kaygısı, uykusuzluk, anoreksiya nervoza, kekemelik, tırnak yeme, sosyal fobi, sahne fobisi vb. zorlayıcı durumlarda paradoksal müdahaleleri etkili olduğu konusunda hem davranışçı kuramcılar hem de psikanalitik kuramcılar tarafından yapılan araştırmalar güçlü kanıtlar ortaya koymuştur (Ascher ve Turner, 1980: 122; Fabry, 1982: 27; Worden, 2013: 182). Günümüzde bu tekniklerin etkililiğine ilişkin yeni deneysel 
çalışmalara intiyaç duyulduğu yadsınamaz bir gerçek olarak karşımıza çıkmaktadır.

Mevcut çalışmanın bir takım sınırlılıkları mevcut olup bir sonraki kısımda ele alınan öneriler bu kapsamda düşünülmelidir. İlk ve en önemli sınırlılık, araştırma yöntem açısından sadece alan yazına dayanmakta ve Türkiye'deki bir üniversitenin veri tabanı ve Google Scholar'da bulunan Türkçe ve/ya İngilizce makalelerle sınırlıdır. İkinci bir sınırılık ise alanyazın taramasını sadece yazar olan iki kişi yapmıştır. Bu sınırlılıkların yanında başka sınırlıııkların da olması da olasıdır.

Bu araştırmanın sınırlılıkları göz önünde bulundurularak elde edilen bulguların (1) ruh sağlığı alanında araştırma, (2) aktif bir şekilde verilen hizmetlerde ve (3) ruh sağlığı eğitimi ve süpervizyonu olmak üzere üç temel alanda aşağıda uygulama önerileri düşünülebilir.

Araştırma alanındaki öneriler; paradoksal müdahalelerin bireysel danışmanlıkta kullanılmasının yaygınlaşması için Victor Frankl’ın kuramının sistemleştirilmesine dönük yeni çalışmaların yapılması, paradoksal niyet tekniğinin daha ciddi bir şekilde kullanılması yolunda projektör görevi üstleneceği düşünülmektedir. Paradoksal müdahale tekniklerinin kültüre özgü bir şekilde yeniden yapılandırılması için yeni çalışmaların yapılması yerinde olacaktır. Paradoksal müdahale tekniğinin aile terapisinin dışında, bireysel terapideki uygulamaları ile ilgili çalışmaların yapılması yeni çalışmalara kaynaklık edeceği düşünülmektedir. Yeni araştırmalar için veya ileride yapılacak benzer araştırmalarda ERIC, Psyclnfo, Education Full Text, and Web of Science, Scopus gibi farklı veri tabanları da kullanılabilir. Ayrıca sadece iki araştırmacı yerine daha fazla araştırmacı ile daha sistematik alan yazın taraması yapılabilir. Başka araştırmacıların da önerdiği gibi Türkiye'de ruh sağlığı alanında yarı-deneysel 
veya deneysel çalışmalar eksik olduğundan (Tanhan, 2018: 50; 2019: 61; Tanhan vd., 2020: 5) ileriki araştırmalarda paradoksal müdahaleler yarı-deneysel ya da deneysel çalışmalarda kullanılıp etkisi incelenebilir. Son bir uygulama önerisi ise paradoksal perspektifler içeren daha genel araştırma yöntemleri ruh sağlığı alanında geliştirmek olabilir. Örneğin, bazı araştırmacılar paradoksal bir perspektiften hareketle ruh sağlığı alanında kişilere hayatlarını kolaylaştıran ve zorlaştıran faktörleri birbiri ardı sıra sorarak daha anlamlı ve zengin sonuçlar almıştır (Tanhan, 2020: 8; Tanhan ve Strack, 2020: 4). Bu araştırmacılar paradoksal bir müdahale içeren Online Seslifoto (OSF) tekniğini geliştirmiş ve OSF'yi pandemi, endemi ya da güvenlik sorunlarının olduğu ve insanların yüz yüze buluşmasının zor olduğu zamanlarda bile çok etkili bir şekilde kullanmışlardır.

Ruh sağlığı alanı için öneriler; ruh sağlığı uzmanları hizmet verirken mevcut makalenin sonuçlarından faydalanabilir. İlk uygulama önerisi, ruh sağlığı uzmanları bu makalede ele alınan paradoksal müdahalelerden danışanın bağlamına da uygun bulduklarını kullanabilir. İkinci uygulama, bu konudaki özellikle de Türkçe alan yazındaki çalışma eksiklikleri de düşünülerek aktif hizmet sağlayanlar araştırmacılarla işbirliği yapılarak hem araştırma hem de aktif ruh sağlığı hizmetlerinin etkisi artırabilir. Üçüncü öneri ise, özellikle deneysel çalışmalarda elde edilen sonuçlarıyla gittikçe önem kazanan Kabul ve Kararlılık Terapisinin (KAT) paradoksal müdahaleleri kullanılabilir ve araştırmacılarla işbirliği içinde ampirik bir şekilde bu müdahalelerin çeşitliliği arttırılabilir.

Ruh sağlığı eğitimi ve süpervizyonu için öneriler; Türkiye'de ve dünyada ruh sağlığı eğitimi ve süpervizyonu hem de araştırmalarda hakkettiği yeri bulmamıştır halbuki ruh sağlığı eğitiminde geleceğin ruh sağlığı uzmanları insanı biyopsikososyal manevi ve ekonomik olarak bütüncül bir şekilde tanımalı (Tanhan, 2019:63; 2020:14; Tanhan vd., 2020:7). Bunun için de uygulamalar ve 
bu uygulamaların sağlıklı bir şekilde yürümesi için süpervizyon gerekmektedir (Tanhan, 2018: 50). Bu konuda ilk uygulama önerisi ruh sağlığı eğitimcilerinin öğrencilere paradoksal müdahaleler hakkında bilgi ve okuma verdikten sonra onlarla sınıf içinde güvenli bir şekilde uygulamalar yapabilir. İkinci bir öneri ise danışan görmeye başlayan ruh sağığı adayları süpervizyon eşliğinde ve danışanla terapötik ilişki kurulduktan sonra danışanın bağlamına uyması durumunda paradoksal müdahale kullanmaya teşvik edilmesi. Ancak bu daha çok mevsim görmüş ruh sağlığı uzmanları ve en az yüksek lisans derecesi almış ruh sağlığı uzman adayı ile kullanılması daha güvenli ve etkili olabilir. Son bir uygulama ise ruh sağlığı eğitimi ve özellikle de süpervizyonda paradoksal yöntemleri daha iyi anlamaları ve hissetmeleri için bu yöntemlerin ders ve özellikle de süpervizyon süpervizör tarafından aday için kullanılması olabilir. 


\section{KAYNAKÇA}

Altıntaş, E., \& Gültekin, M. (2005). Psikolojik danışma kuramları. İstanbul: Aktüel Yayıncılık.

Ascher, L. M., \& Schotte, D. E. (1999). Paradoxical intention and recursive anxiety. Journal of Behavior Therapy and Experimental Psychiatry, 30, 71-79.

Ascher, L. M., Schotte, D. E., ve Grayson, J. B. (1986). Enhancing Effectiveness of Paradoxical Intention in Treating Travel Restriction in Agoraphobia. Behaviour Therapy, 17(2), 124-130.

Ascher, L. M., ve Turner, R. M. (1980). A comparison of two Methods for the Administration of Paradoxical Intention. Behaviour Research and Therapy, 18(2), 121-126.

Baltacı, Ö. (2016). Paradoksal psnikoterapi. Cumhuriyet International Journal of Education, 5 (2), 1-8.

Becvar, D.S., \& Becvar, R. J. (1998). Family therapy: A systemic integration. Boston: Allyn and Bacon.

Brown, J. H., \& Christensen, D. N. (1999). Family therapy: Theory and practice. Pacific Crove: Book/Cole.

Budak, S. (2005). Psikoloji terimler sözlüğü. Ankara: Bilim ve Sanat Yayınları.

Carlson, J., Watts, R. E., \& Maniacci, M. (2006). Adlerian therapy. Washington, DC: American Psychological Association.

Cooper, M. (2016). Existential therapies. London: Sage.

Dallos, R., \& Draper, R. (2012). Aile terapisine giriş sistemik teori ve uygulamalar. Çev. Ed. Şahin Kesici. İstanbul: Nobel Yayınevi.

DiTomasso, R. A., \& Greenberg, R. L. (1989). Paradoxical intention: The case of the case study. In L. M. Ascher (Ed.), Therapeutic paradox. New York: Guilford Press. 
Dowd, E. T., \& Milne, C. R. (1986). Paradoxical interventions in counseling psychology. The Counseling Psychologist, 14, 237-282.

Fabry, J. (1982). Some Practical Hints About Paradoxical Intention. International Forum for Logotherapy, 1(5), 25-29.

Frankl, V. E. (2009). Duyulmayan anlam çığlığı: Psikoterapi ve hümanizm.Çev., Selçuk Budak. İstanbul: Ötüken Yayınevi.

Frankl, V. E. (2013). İnsanın anlam arayışı. Çev., Selçuk Budak.İstanbul: Okuyan Us Yayınları.

Gladding, S.T. (2012). Aile Terapisi Tarihi Kuram ve Uygulamaları. Çev. Ed. İbrahim Keklik ve İbrahim Yıldırım. Ankara: PDR Derneği Yayınları.

Goldenberg, I. ve Goldenberg, H. (2008). Family therapy: An overview. Belmont, CA: Books/Cole.

Hackney, H., ve Cormier, S. (2008). Psikolojik danışma ilke ve teknikleri: Psikolojik yardım süreci el kitabı. Çev., Tuncay Ergene ve Seher Aydemir-Sevim. Ankara: Mentis Yayıncılık.

Haley, J., \& Richeport-Haley, M. (2003). The art of strategic therapy. New York: Brunner-Rootledge.

Kesici, Ş., İlgün, E., Mert, A., ve Büyükbayraktar-Girgin, Ç. (2013). Aile terapisinde kullanılan teknikler. Ankara: Nobel Yayınları.

Mills, M. A. (2000). Paradoxical intervention with severe conduct-disorder in adolosecents: Research of treatment effectiveness. (Unpublished doktoral thesis), Wets Virginia University, Morgantown.

Murdock, N.L. (2013). Psikolojik danışma ve psikoterapi kuramları: Olgu sunumu yaklaşımıyla. Çev.Ed., Füsun Akkoyun . Ankara: Nobel Yayınevi.

Nazlı, S. (2014). Aile Danışmanlığı (11. Baskı). Ankara: Anı Yayıncılık.

Nichols, M. P. (2013). Aile Terapisi: Kavramlar ve Yöntemler. Çev., Okhan Gündüz. İstanbul: Kaknüs Yayınları. 
Nietzel, M.T., Bernstein, A.D., Kramer, G.P., \& Milich, R. (2003). Introduction to Clinical Psychology. New Jersey: Pearson.

Ünal, S. (2013). Sistemik aile terapilerinde temel kavramlar. Turkiye Klinikleri Psychiatry-Special Topics, 6(1), 32-37.

Özabacı, N., \& Erkan, Z. (2013). Aile danışmanlığı : Kuram ve uygulamalara genel bir bakış. Ankara: Pegem Akademi.

Özburun, N. (2018). Derleme: Genel sistem teorisinden etkilenen aile terapisi modellerinin karşılaştırılması. Türkiye Bütüncül Psikoterapi Dergisi, 1(2), 172-188.

Palazzoli, M., Cirillo, S., Sorrentino, A. M. (1989). Family games: General model of psychotic processes in the family. New York: W W Norton \& Company.

Prinz, J., \& Arkin, S. (1994). Adlerian group therapy with substance abusers. Individual Psychology. The Journal of Adlerian Theory, Research \& Practice, 50(3), 349-358.

Riebel, L.K. (1981). Theconsept of paradox as a construct in psychotherapy. (Unpublished Doctoral Thesis), Saybrook Universtiy, Oakland.

Rohrbaugh, M., Tennen, H., Press, S., \& White, L. (1981). Compliance, defiance, and therapeutic paradox: Guidelines for strategic use of paradoxical interventions. American Journal of Orthopsychiatry, 51(3), 454-467.

Seligman, L. (2001). Systems, strategies, and skills of counseling and psychotherapy. Upper Saddle River, NJ: Prentice-Hall.

Sharf, R. S. (2014). Theories of psyhotherapy and counseling concepts and cases. Belmont: Brooks/Cole Cengage Learning.

Shoham-Salomon, V., Rosenthal, R. (1987). Paradoxical interventions: A metaanalysis. Journal of Consulting and Clinical Psychology, 55(1),22-28.

Sparrer, I. (2011). Çözüm odaklı yaklaşıma ve sistemik yapısal dizime giriş. Çev., Esin Suvarierol. İstanbul: Pan Yayıncılık. 
Tanhan, A. (2018). Beginning counselors' supervision in counseling and challenges and supports they experience: Based on developmental models. Adıyaman Üniversitesi $\quad$ Eğitim Bilimleri Dergisi, 8(1), 49-71.

Tanhan, A. (2019). Acceptance and commitment therapy with ecological systems theory: Addressing they experience: Based on developmental models. Adıyaman Üniversitesi Eğitim Bilimleri Dergisi, 8(1), 49-71. doi:10.17984/adyuebd.336222.

Tanhan, A. (2020). COVID-19 Sürecinde online seslifoto ile biyopsikososyal manevi ve ekonomik meseleleri ve genel iyi oluş düzeyini ele almak. Manuscript under review.

Tanhan, A., Yavuz K. F., Young, J. S., Nalbant, A., Arslan, G., Yıldırım, M., Ulusoy, S., Genç, E., Uğur, E., \& Çiçek, İ. (2020). A proposed framework based on literature review of online contextual mental health services to enhance wellbeing and address psychopathology during COVID19.Electronic Journal of General Medicine, 17(6), em254. https://doi.org/10.29333/ejgm/8316.

Tanhan, A., \& Strack, R. W. (2020). Online photovoice to explore and advocate for Muslim biopsychosocial spiritual wellbeing and issues: Ecological systems theory and ally development. Current Psychology, 1-16. https://doi.org/10.1007/s12144-020-00692-6.

Watzlawick, P., Weakland, J., \& Fsch, R. (1974). Change: Principles of problem formation and problem resolution. New York: W.W. Norton.

Weeks, G. R. (2013). Promoting change through paradoxical therapy. New York: Routledge.

Worden, M. (2013). Aile terapisi temelleri. Çev. Ed. Turan Akbaş. Adana: Adana Nobel Kitabevi. 


\section{EXTENDED ABSTRACT}

\section{Introduction}

Mental health professionals', as researchers or practitioners, familiarity and use of different interventions is crucial to serve their clients to address their biopsychosocial spiritual issues or enhance their wellbeing (Tanhan, 2018: 49; 2019: 200). Therefore, in this study we examined paradoxical techniques used in therapy to inform readers (a) about the background of these techniques and (b) how these techniques could be utilized effectively for a more productive counseling process. Paradoxical intervention techniques are more likely to enable clients or consultees to look at their issues from a different (e.g., creative hopelessness, exaggeration, humor) perspectives and gain a sense of self-control over the issue. Practitioners used the techniques to bring a different perspective to address clients' issues when other normal interventions (e.g., empathy, reflection of feelings, reflection of content, confrontation) do not work. Practitioners applied these techniques as a last option and found them helpful (Mills, 2000: 8). The practitioners implement paradoxical techniques to make the client conduct the unwanted behavioral, emotional, or cognitive patterns more and intensive for a period of time to bring a different perspective that the client is not able to recognize. In general, the techniques are classified under behaviorism, and yet many therapies apply them including acceptance and commitment therapy (Tanhan, 2019: 201-202), brief, problem focused therapy (Rohrbaugh et al., 1981: 454), dialectical behavioral therapy, strategic family therapy, logotherapy, cognitive therapy, psychodynamic therapy and other postmodern therapies (Frankl, 2013: 140; Mills, 2000: 9). Paradoxical interventions have been criticized for different reasons (Özburun, 2018: 184) yet they have been utilized as alternatives for years owing to being effective as much as normal interventions (Rohrbaugh et al., 1981: 454; Shoham-Salomon \& Rosenthal, 1987: 24; Tanhan, 2019: 201-202). 


\section{Method}

This study is a literature review and yet we did not follow a systematical approach due to lack of studies including paradoxical interventions. We have included any printed work including books, dissertations, and manuscripts. We entered "paradoxical intervention" and "paradoxical interventions in therapy" in Turkish and English in a database of a university in Turkey and Google Scholar. We included any studies included one or both of the keywords.

\section{Findings (Results)}

Based on the results, there are some main person and therapies stressing paradoxical interventions. As the main persons we came across Knight Dunlap who conducted studies in 1920s utilizing "negative application" procedures for different issues including eating nails, enuresis, tics, stuttering (Riebel, 1981: 22). Alfred Adler is also another person who defined paradoxical intervention as prescribing symptoms (Sharf, 2014: 128). He also used humor with paradoxical techniques (Mills, 2000: 8; Sharf, 2014: 128 ). The next person is Viktor Frankl who is known for using paradoxical techniques as a therapeutic technique, like Adler, and systematized the paradoxical techniques. Viktor developed paradoxical intention as a concept as a part of his logo therapy, which is one of the therapies applying paradoxical techniques at most (Weeks, 2013: 73).

In terms of therapies, Milton Erikson's strategic family therapies contributed to the use of paradoxical techniques (Mills, 2000: 34). In this approach, the therapist suggests a paradoxical, meaning a controversial, suggestion to the family so that the family can accept it and gain control over the problem or reject it and can get over the issue (Dallos ve Draper, 2012: 54; Worden, 2013: 182). Another therapy in which paradoxical techniques could be used is Acceptance and Commitment Therapy (ACT) because one of the main columns of ACT is its two models: psychological flexibility and inflexibility model (Tanhan, 2019: 201-202). He explained how these two models could be considered as 
two poles of a spectrum. Psychological flexibility model explains normal (or positive) human psychology and the model comprises six main processes (e.g., flexible attention to the present moment, self-as-content) and psychological inflexibility model explains human psychopathology and comprises six processes (e.g., inflexible attention to the present moment, self-as-context) (Tanhan, 2019: 201). Based on these processes, an ACT therapist can utilize the psychological inflexibility processes as paradoxical techniques (e.g., creative hopelessness, fused on ideas, self-as-content) when all other ways are not effective. Based on the results, it seems there are two main ways to use of paradoxical techniques: paradoxical intention and paradoxical application (intervention). There are some specific and common paradoxical techniques including different versions of redefining (Murdock, 2013: 441; Özabacı \& Erkan, 2013: 62; Goldenberg \& Goldenberg, 2008: 227; Hackney \& Cormier, 2008: 195; Watzlawic et al., 1994; Worden, 2013: 183-184), prescribing (Dowd \& Milne, 1986: 263; Hackney \& Cormier, 2008: 197; Murdock, 2013: 442; Weakland et al., 1974; Worden, 2013: 184), and restraining (Murdock, 2013: 442; Worden, 2013: 184). An important point is novice counselors should stay away from attempts use paradoxical techniques. They may use such techniques as long as they receive a well-structured supervision process (Gladding, 2012: 377).

\section{Conculusion and Discussion}

Paradoxical techniques have been discussed and utilized for many years, and mental health providers could utilize them especially when all other traditional therapeutic interventions do not function. The use of the techniques may be more effective when the clients show fixed, rigid, and repetitive patterns and are far away from looking at the issues from a different perspective. Counsellors need to be careful when they apply paradoxical techniques and need to have a strong therapeutic alliance and a sense of how the clients are functioning (Worden, 2013: 176-178) or they could use them under well-structured 
supervision (Gladding, 2012: 377), which is one of the most elements of training to train mental health providers in-training (Tanhan, 2018: 49). The use of the techniques is as effective as the other traditional techniques (Baltacı, 2016: 7), which is supported by some main counseling approaches (e.g., ACT, cognitive therapy) to address diverse issues (Ascher \&Turner, 1980: 122; Fabry, 1982: 27; Riebel, 1981: 32; Worden, 2013: 182). Paradoxical techniques also could be utilized in accordance with other commonly used techniques to address the issues and enhance wellbeing (Ascher et al., 1986: 126; Nietzel et al., 2003: 46). The mental health trainers as gatekeepers for novice counselors, researchers, and practitioners can pay more attention to the use of such techniques and use different models (Tanhan, 2018: 68) to enable future counselors use paradoxical interventions and related specific techniques. 